\title{
Microscopical Observations on the Microsporidians Isolated from Insect Pests
}

\author{
Ifat Bashir ${ }^{1}$ and Shabir A. Bhat ${ }^{2 *}$ \\ ${ }^{1}$ Department of Sericulture, Govt. Degree College for Boys, Sopore, Kashmir, India \\ ${ }^{2}$ College of Temperate Sericulture (COTS) Mirgund, Sher-e-Kashmir University of \\ Agricultural Sciences and Technology of Kashmir, Srinagar, India \\ *Corresponding author
}

\section{A B S T R A C T}

\begin{tabular}{l} 
K e y w o r d s \\
$\begin{array}{l}\text { Insect, Mulberry, } \\
\text { Microsporidian, } \\
\text { Nosema bombycis, } \\
\text { etc. }\end{array}$ \\
\hline Article Info \\
\hline $\begin{array}{l}\text { Accepted: } \\
07 \text { October } 2020 \\
\text { Available Online: } \\
10 \text { November } 2020\end{array}$ \\
\hline
\end{tabular}

Keywords

Insect, Mulberry, Microsporidian, Nosema bombycis, 10 November 2020
Morphological observations on the microsporidian spores from Catopsilia crocale, Catopsilia pyranthe, Diaphania pulverulentalis, Pieris rapae and Spilosoma oblique were recorded in the present paper. The spores were provisionally designated as NIK-1Cc, NIK-1Cpy, NIK-1Dp, NIK-1Pr, NIK-1So. Wherein NIK represents "National Institute Karnataka" and Cc, Cpy, Dp, Pr and So represent the first letters of the generic and species name of the insect pest from which these microsporidians were isolated. The spore shape of NIK-1Cc, NIK1Cpy, NIK-1Dp were oval and NIK-1Pr, NIK-1So were ovo-cylindrical. However the spores of standard strain Nosema bombycis was oval in shape also. The scanning electron microphotographs of all microsporidian including $N$. bombycis indicated that the surface of spores was smooth in texture.

\section{Introduction}

Microsporidia are found infecting nearly all insects orders but over half of the susceptible insect hosts occur in two orders, Lepidoptera and Diptera.

Most of the entomopathogenic microsporidia occur in genus Nosema, more than 150 described species found in 12 orders of insects (Becnel and Andreadis, 1999). Different microsporidian isolates have been reported to be isolated from silkworm Bombyx mori in India (Bhat and Nataraju,
2004; Selvakumar et al., 2005; Bhat et al., 2009a).

The early descriptions of microspridian were mainly based on spore morphology and lack ultra structural details but in the recent identification it was necessary to use at least a minimum of ultrastructural characters (Larson, 1988).

We report herein, the morphological characteristic features of five different microsporidians isolated from insect pests of mulberry and agricultural crops. 


\section{Materials and Methods}

\section{Microsporidian isolates}

Eleven (11) different insect pests of mulberry and agricultural crops were collected separately from mulberry garden and agricultural fields. The insects were homogenized and the smear was examined under microscope for microsporidian infection. Only five out of eleven insects were found infected with microsporidian infection which were collected and purified by the method described by Sato and Watanabe (1980). The standard strain Nosema bombycis were collected from the Silkworm Pathology Laboratory, Central Sericultural Research and Training Institute Mysore for comparison. The micro-photographs were taken using phase contrast microscope Nikon (Type 104) at $600 \mathrm{x}$ magnifications for determination of spore shape.

The purified spores were air dried at room temperature for electron microscopic studies. The samples were transferred onto double stick cellophane tape pasted on copper stubs used for mounting specimen for scanning electron microscopy. The mounted stubs were coated with about $20 \mathrm{~nm}$ gold in sputter coater (EMS-550) and viewed under JEOL$100 \mathrm{CX}-\mathrm{II}$ electron microscope fitted with an ASID-4D scanning attachment (Tokyo, Japan $20 \mathrm{KV}$ ). The spores were observed and photographed to study the spore shape, surface and compared with that of $N$. bombycis.

\section{Results and Discussion}

The microsporidian spores from Pieris rapae, Catopsilia crocale, Catopsilia pyranthe, Spilosoma obliqua and Diaphania pulverulentalis were ovocylindrical, oval, oval, ovocylindrical and oval in shape respectively whereas the spore of the standard strain N. bombycis was oval (Table 1; Plate 1). The scanning electron micrographs indicated that the surface of the spores of all the five microsporidia were smooth in texture which is same as that of $N$. bombycis spores (Plate 2). The wet mounts of the microsporidian spores viz., NIK-1Pr, NIK$1 \mathrm{Cc}$, NIK-1Cpy, NIK-1So and NIK-1Dp exhibited characteristic Brownian movement and high refractive index as is exhibited by the $N$. bombycis.

Table.1 Screening of different insect pests of mulberry and other agricultural crops for

\begin{tabular}{|l|l|l|c|c|}
\hline \multicolumn{1}{|c|}{ Insect pest } & Family & Host plant & $\begin{array}{c}\text { Microsporidian } \\
\text { isolates }\end{array}$ & Shape \\
\hline Pieris rapae & Pieridae & $\begin{array}{l}\text { Cabbage, } \\
\text { Cauliflower etc, }\end{array}$ & NIK-1Pr & $\begin{array}{c}\text { Ovo- } \\
\text { cylindrical }\end{array}$ \\
\hline $\begin{array}{l}\text { Catopsilia } \\
\text { crocale }\end{array}$ & Pieridae & $\begin{array}{l}\text { Red gram, Bitter } \\
\text { gourd etc, }\end{array}$ & NIK-1Cc & Oval \\
\hline $\begin{array}{l}\text { Catopsilia } \\
\text { pyranthe }\end{array}$ & Pieridae & $\begin{array}{l}\text { Red gran, River } \\
\text { bean etc }\end{array}$ & NIK-1Cpy & Oval \\
\hline $\begin{array}{l}\text { Spilosoma } \\
\text { obliqua }\end{array}$ & Arctiidae & $\begin{array}{l}\text { Mulberry, Green } \\
\text { gram etc }\end{array}$ & NIK-1So & $\begin{array}{r}\text { Ovo- } \\
\text { cylindrical }\end{array}$ \\
\hline $\begin{array}{l}\text { Diaphania } \\
\text { pulverulentalis }\end{array}$ & Pyralidae & Mulberry & NIK-1Dp & Oval \\
\hline
\end{tabular}


Plate.1 Light microscopic observation on different microsporidians isolated from insect and compared with that of Nosema bombycis (600x)
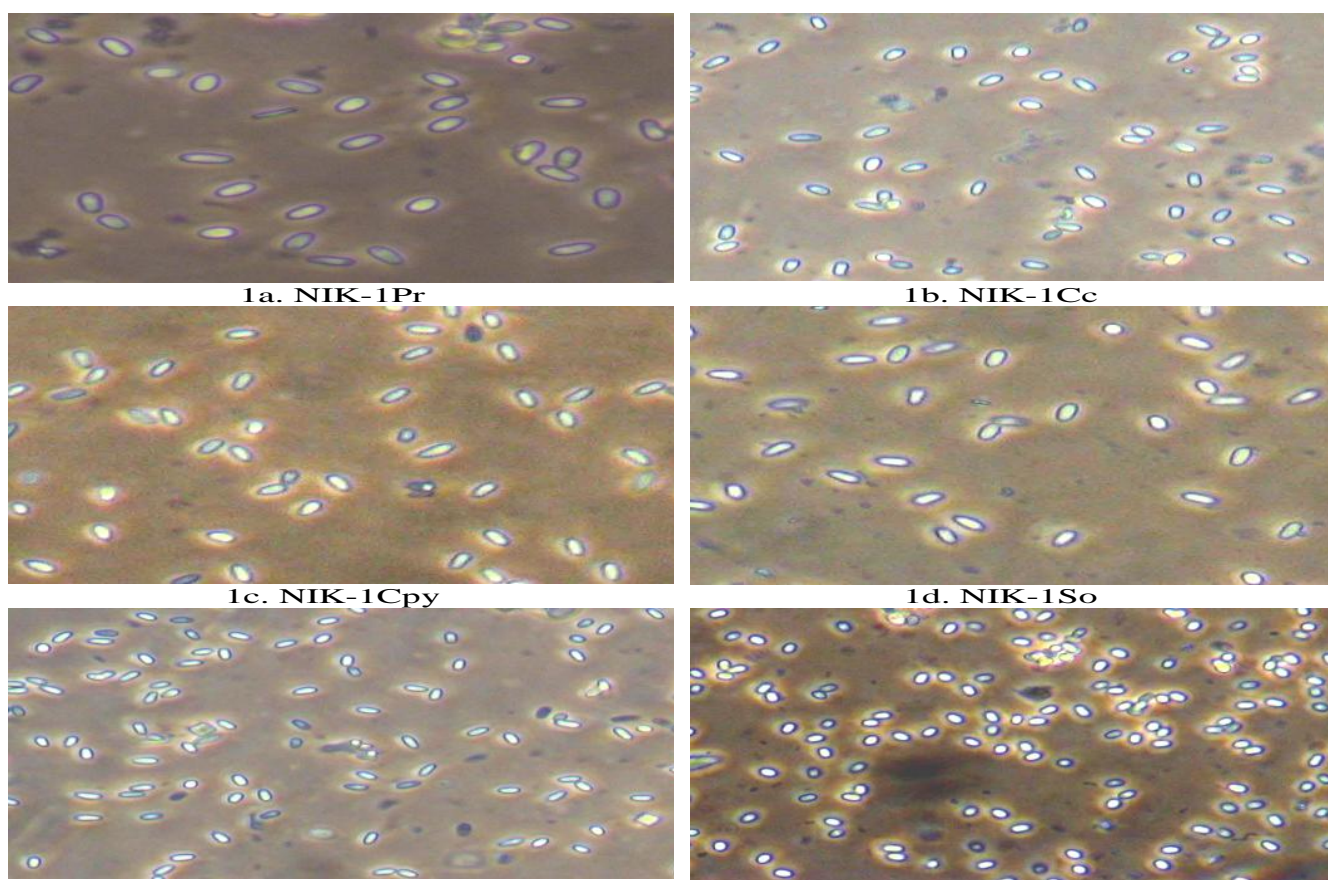

1e. NIK-1Dp

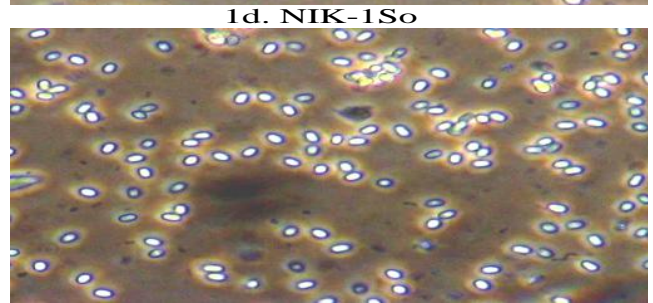

1f. Nosema bombycis

Plate.2 Scanning electron micrograph of microsporidians isolated from insect pests and compared with that of $N$. bombycis (35700x)
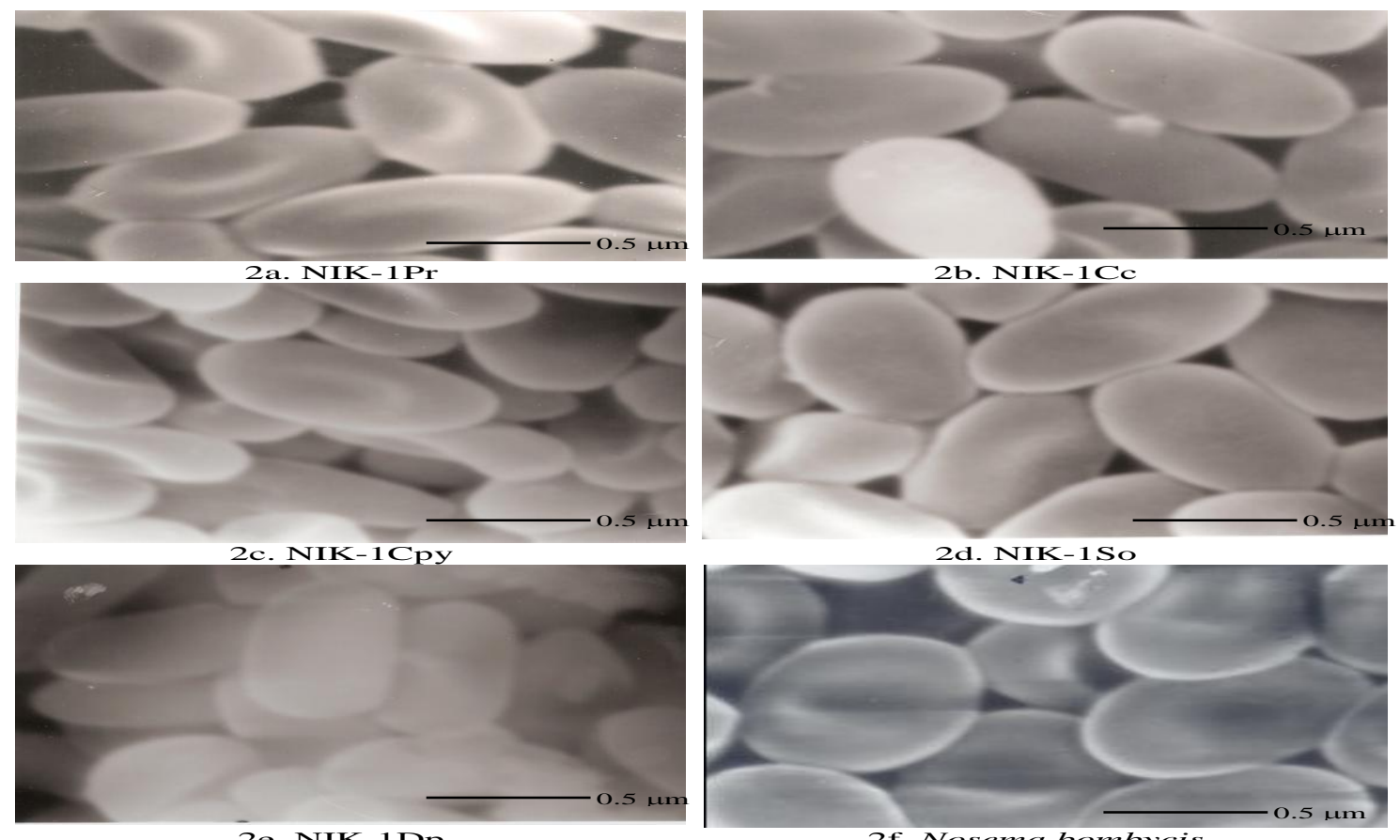

2e. NIK-1DP

2f. Nosema bombycis 
The morphological observations carried out under the present study are of considerable practical as well as academic value in the field of silkworm diseases. This preliminary study shows that they possess all the characteristic features of typical microsporidian. The spores of these microsporidians were oval or ovocylindrical in shape. In addition to N. bombycis, several other microsporidia infect silkworm which differ in spore shape, texture (Kawarabata, 2003; Sasidharan et al., 2003; Singh and Saratchandra, 2003; Bhat et al., 2009b). Sprague (1982) stated that most microsporidian spores are in the size range of 3-6 / 2-4 $\mu \mathrm{m}$, but some are over $20 \mu \mathrm{m}$ in length. The size range of microsporidian spores vary greatly within a single species (Stempellia, Pleistophora) or there may be two distinct sizes (dimorphic) as in Vairimorpha, Burenella, Parathelohania, Amblyospora (Issi, 1986). The surface sculpturing of certain spores, when observed with the scanning electron microscope, are distinct and characteristic and may also serve in classifying the microsporidia (Flower and Reeves, 1975b). The spores of Nosema sp. C01 isolated from Pieris rapae in Korea have been reported to be spherical in shape and the surface sculpturing is crumpled (Choi et al., 2002).The study thus, reveals that the said microspidians isolated from different insect pests of mulberry and other agricultural crops are different from each other and also from standard strain $N$. bombycis. Indeed the taxonomic position of these microspridians to be clarified in further studies.

\section{References}

Becnel J J, Andreadis, T G, Microsporidia in Insects; In "The Microsporidia and Microsporiodiosis." Wittner, M and L. M. Weiss (eds.) pp. 447-501. ASM press, Washington D.C (1999).

Bhat SA, Nataraju, B, Preliminary study on a microsporidian isolate occurring in the Lamerin breed of the silkworm, Bombyx mori L. in India. Int. J. Indust. Entomol. 9 (2004) 265-267.

Bhat SA, Ifat Bashir, Kamili A S, Microsporidiosis of silkworm, Bombyx mori 1 (Lepidoptera- bombycidae) Standard review. African $J$ of Agricultural Research. 4(2009a) 15191523.

Bhat, SA, Ifat B, Nataraju B, Biology of microsporidia infecting silkworm, Bombyx mori L., J. Exp. Zool. 12 (2009b) 241-243.

Choi, JY, Kim JG, Choi YC, Goo TW, Chang JH, Yeon HJ, Kim KY, Nosema sp. isolated from cabbage white butterfly (Pieris rapae) collected in Korea, J. Microb., 40 (2002) 199-204.

Fowler JL, Reeves E L. In vivo propagation of a microsporidian pathogenic to insects. J. Invertebr. Pathol. 25 (1975)349-353.

Issi, I V, Microsporidia as a phylum of parasitic protozoa, Protozoology, (Leningrad) 10(1986) 6-136.

Kawarabata, T, Biology of Microsporidians infecting the silkworm, Bombyx mori, in Japan. Insect Biotech. and Sericol.72 (2003) 1-32.

Larrson, J R, Identification of microsporidian genera (Protozoa, Microspora) - a guide with comments on the taxonomy. Arch. Protistenkd. 136 (1988) 1-37.

Sasidharan TO, Singh RN, Santha P C, Studies on the microsporidiosis of silkworm, Bombyx mori, L. Annual Report- SSTL Bangalore, (2003) pp. 1-3.

Selvakumar T, Nataraju B, Chandrasekharan K, Sharma, SD, Balavenkatasubbaiah M, Sudhakara Rao P, Thiagarajan V, Dandin, $\mathrm{S} \mathrm{B}$, Isolation of a new microsporidian sp. (NIK-5hm) forming spores within the haemocytes of silkworm, B.mori L. Int. J. Indust. 
Entomol. 11 (2005) 63-66.

Singh T, Saratchandra B, Microsporidian disease of the silkworm Bombyx mori L. (Lepidoptera: Bombycidae) Int. J. Indust. Entomol. 6 (2003) 1-9.
Sprague V, Microspora. In "Synopsis and Classification of Living organisms", (S.P Parker,ed.) Vol. 1. Pp. 589-594, McGraw-Hill, New York (1982).

\section{How to cite this article:}

Ifat Bashir and Shabir A. Bhat. 2020. Microscopical Observations on the Microsporidians Isolated from Insect Pests. Int.J.Curr.Microbiol.App.Sci. 9(11): 744-748.

doi: https://doi.org/10.20546/ijcmas.2020.911.089 